\title{
К ВОПРОСУ О СЕМИОТИКЕ ПРОСТРАНСТВА СРЕДНЕВЕКОВОГО ГОРОДИЩА КАСТЕК: ФУНКЦИОНАЛЬНЫЙ АНАЛИЗ АРТЕФАКТОВ
}

\author{
(C) 2018 г. А.А. Нуржанов
}

\begin{abstract}
В эпоху тюркского каганата и последующих этнокультурных и государственных образований с тюркоязычной политической доминантой процесс урбанизации в маргинальных зонах оседло-земледельческой культуры все более усиливался. В домонгольскую эпоху здесь прочно складывается локальный урбанистический комплекс с общемусульманскими стандартами и эталонами в его средневековом воплощении, пестрым многоязычием и этнической ассимиляцией согдийцев и различных тюркоязычных народов в рамках Караханидского государства, которое являет собой образец средневековой урбанизированной культуры. Также на материалах артефактов, найденных в ходе раскопок, произведена реконструкция некоторых ритуальных и повседневных практик, характерных для городской культуры средневековых тюрков Жетысу. Функциональный анализ артефактов доказывает, что утилитарные предметы и действия в традиционной культуре пронизаны символами и существуют в равной степени как предмет быта, и сакральное произведение искусства городской культуры тюрков.

Ключевые слова: археология, Жетысу, средневековье, семиотика пространства, средневековая урбанистика, тюрки, карлуки, караханиды, тюркская городская культура, религия, цивилизация, сакральные артефакты
\end{abstract}

В тюркской культуре феномен города многогранен, полифункционален и имеет свою социокультурную специфику. Интересным представляется вопрос кросс-культурного взаимовлияния средневековых тюркских городов на социально-экономические, военно-политические и религиозные импульсы тюркских государств как уникальной этнокультурной среды.

Семиотика, как комплекс методологий, применяемых в социогуманитарных науках, исследует знаковые системы, культурные коды, системы коммуникаций, мировосприятие. Пространство средневекового города является, кроме всего прочего, знаковой системой культурных смыслов, воплощенных в архитектуре, то- понимике и производимых артефактов. Функционируя как пространство урбанизированной идентичности, средневековый город вырабатывает социокультурные импульсы, отражающие и формирующие тот уникальный тип культуры, семантику и семиотику которого исследуют археологи, историки, культурологи и т.д.

На сегодняшний день интердисциплинарное исследование ментальной культуры, воплощенной в материальной культуре, артефактах, ритуальных комплексах и сакральных памятниках, является одним из самых перспективных направлений гуманитарного познания. Изучение истории ментальностей актуально также и в силу константности базовых меха- 
Нуржанов А.А. К вопросу о семиотике пространства средневекового городища Кастек...

низмов человеческого мышления, в течение тысячелетий циркулирующего по каналам культуры и детерминированных закономерностями функционирования человеческой психики. С другой стороны, интерпретация материальной культуры исключительно как знаковой системы - не всегда продуктивна. Эпистемологические конфликты такого рода ведут к смене парадигм, в частности, исследования культурогенеза последовательно прошли через антропологический, семиотический, лингвистический, онтологический и др. повороты.

Ментальная и материальная культуры горожан тюркских каганатов, с одной стороны, прошла несколько этапов своей эволюции, с другой, как и любая культура, развивалась в активном взаимодействии и взаимовлиянии с культурами других народов, как родственных кочевых, так и оседлых (согдийская, китайская). Оба эти процесса нашли отражение в археологическом материале. Древние тюрки, объединив, пусть и на короткий период, большую часть Евразии в рамках Первого Тюркского каганата, способствовали активизации межкультурных и межэтнических контактов.

Образование и развитие тюркских городов Средней Азии и Казахстана, при всех общих закономерностях, не было шаблонным, имело свои особенности. Структура средневековых городов также не была единой и зависела от объективных условий процесса градообразования. Этот вывод особенно важен и справедлив для средневекового Казахстана, где формирование городских центров происходило в условиях исторически сложившегося взаимодействия оседло-земледельческого и кочевого населения, что сказалось на топографии и типах городов, своеобразии го- родской культуры. В известных древнетюркских «рунических» памятниках на p. Орхоне (эпитафии Кюльтегина, Бильге-кагана и Тоньюкука) употреблены собственно тюркские термины: «балык» - город, «балыкдакы» - горожане, «барк» - здание.

В первые десятилетия VII в. на трассе Великого Шелкового пути, переместившегося в Южный Казахстан и Жетысу, появились города. Некоторые из них сформировались как ставки тюркских каганатов, другие были основаны согдийцами как торговые фактории. Доля оседлого и городского населения увеличивалась вплоть до начала XIII в. То есть, на протяжении шести-семи столетий в рамках таких государств, как Тюркский, ЗападноТюркский, Тюргешский, Карлукский, Караханидский каганаты характерно сочетание скотоводства и земледелия, сопровождающееся ростом и расширением последнего, появлением селений и городов.

Жетысу занимает ШуБалхашский бассейн, средняя высота которого колеблется в пределах 300-400 м над уровнем моря, наиболее низкое место - низовья р. Шу. Продольная ось Шу-Балхашского междуречья проходит через низовья Шу-Балхаш, оз. Алаколь и через Жонгарские ворота уходит в Западный Китай, к озеру Эби-Нор.

К югу от реки Иле начинается Илейский/Заилийский Алатау. Западная часть между правым берегом p. Шу и песками, окаймляющими нижнее течение р. Иле, называется Шу-Илейскими горами, отдельные части которых носят название Кулжабасы, Хантау, Козыбасы. Они имеют многочисленные перевалы, удобные для колесного транспорта. Через Кордайский перевал проходит дорога, соединяющая Илейскую и Шуйскую 
долины. Еще один путь проходит через перевал Кастек, соединяя долину Иле с котловиной Иссык-Куля и долиной Шу.

Шу-Илейская долина на протяжении нескольких столетий была центром городской культуры Тюркских государств. Последнее доказывается топонимическими и гидронимическими наименованиями, сохранившими трансформированное звучание имен первых каганов (ататюрков) - основателей древнетюркского государства. Так, имя первого кагана - Бумыня (кит. Тумыня) сохранилось в гидрониме p. Иле, протекающей ныне по территории Западного Китая и Казахстана и впадающей в озеро Балхаш. Этот гидроним, несомненно, реконструируется как «эль-эли» или «иль-или» рунических надписей в смысле «племя», союз племен, государство. Более того, Н.Я. Бичурин имя Или Бумыня напрямую связывает с названием семиреченской реки и комментирует это так: Или-хан значит «хан с реки Или» [Бичурин, 1950, с. 227]. После смерти Бумыня в 552 г. престол тюркского эля занимает его сын Коло, правивший всего год (ум. в 553 г.), но успевший принять имя Исиги-хана [Бичурин, 1950, с. 28, прим. 4], лакаб (престольное имя) связываем с гидронимом ИсикЕсик (оз. Иссык). От следующего гидронима, реки Кеген, происходит лакаб Мукан-хана (время правления 553-572 гг.) - младшего брата Есигихана. Его имя известно как Муюй (Мухан)-хан Кигин [Бичурин, 1950, c. 227-228].

Перевал Кастек издревле служил для связи долин р. Шу и Иле. Упоминание об этом перевале сохранилось в источниках XV в., описывающих поход Тимура. В 1375 г. армия Тимура из долины Иле шла в Атбаш через перевал Кара-Касман (Кастек).

Средневековое городище Кастек-1 находится в 2,5 км от с. Кастек, на левом побережье р. Кастек у подножья горы Суыктобе. Географические координаты: $43^{\circ} 03^{\prime} 03,54$ »C; $75^{\circ} 59^{\prime} 09,11 » \mathrm{~B}$, на высоте 1296 м над уровнем моря. Городище расположено на месте выхода горной речки из горных теснин на относительно широкую часть возвышенных прилавков, образующих возвышенное плато, при этом река еще сохраняет стремительность своего течения, создавая своеобразный звуковой фон местности.

Центральная часть памятника представляет собой несколько возвышенный над общей поверхностью подчетырехугольный участок, ориентированный углами по сторонам света. Общая площадь городища составляет 30 га. Цитадель размерами по линии С-Ю - 210 м, В-3 - 150 м, что составляет 4 га. Он обнесен крепостной стеной, которая выглядит как оплывший вал толщиной до 15 м, высотой до 4 м. По гребню вала видны впадины и всхолмления на месте оборонительных башен. В топографии городища выделяются 14 башен и 32 крупных домовладения, располагавшихся внутри стен, имеется и значительное число других построек, расположенных, главным образом, вдоль реки. Вокруг вала с трех сторон, кроме восточной, прослеживается ложбина былого рва глубиной 0,5-2 м и шириной 3-4 м. Восточной стороной город располагался на высоком берегу реки, остатков построек на нем не зафиксировано. Въезды находятся напротив друг друга в середине стен.

Общая площадь раскопа составила 5000 кв.м. Раскопано: два тюркокарлукских слоя, относящихся ко второй половине VII - первой половине $\mathrm{X}$ вв., а также три строительных гори- 
Нуржсанов А.А. К вопросу о семиотике пространства средневекового городища Кастек...

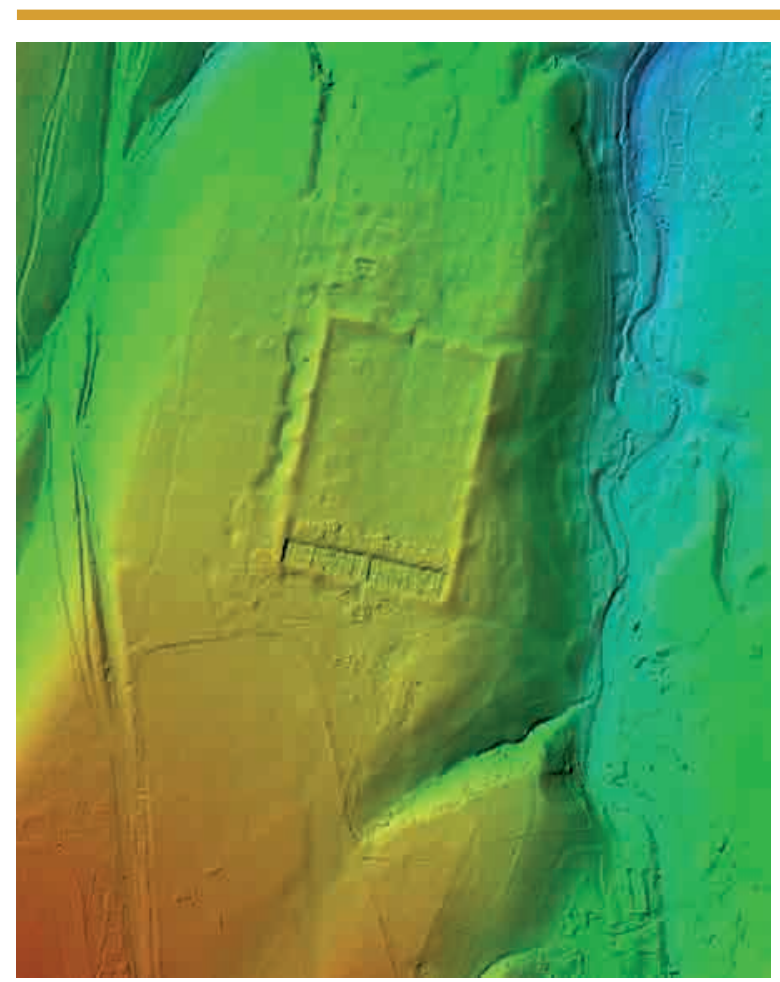

Семиотика повседневности исследована в найденных на территории средневекового города Кастек артефактах. В полевом сезоне 2018 г. было найдено большое количество уникальных находок. Особенно выделяются: шахматная фигура; хирургические инструмены; ритуальные сосуды; предметы вооружения; ножи и др. Кратко охарактеризуем предметы.

Шахматная фигура вырезана из слоновой кости. Изготовлена как зооморфная стилизация птицы Рух (аналог фигуры «слон»). Это свидетельствует не только об интенсивных экономических контактах жителей настоящего региона с другими оседло-

Рис. 1. Городище Кастек. Снимок предоставлен Дин Яном

Fig. 1. Kastek settlement. Photo by Ding Yan зонта, относящихся к Караханидскому периоду (вторая половина $\mathrm{X}$ - первая половина XIII вв.) (рис. 1;2).

У юго-восточной стены расположен глиняный алтарь с двумя полуовальными ступенями (рис. 3). На верхней плоскости алтаря - углубление в виде чаши из обожженной глины диаметром 40 см. Поверхность чаши украшена наклонными прочерченными линиями. С двух сторон от нее находятся два шишковидных выступа диаметром около 8 см. На полу вблизи алтаря - очаг диаметром 52 см. У входа в помещение стоял керамический сосуд с отбитым верхом. Вдоль северной стены расположена суфа шириной 80 см. Помещение 1 объединяется проходами с помещениями 2 и 3. земледельческими цивилизациями, но и о наличии игровой культуры и распространенности игры в шахматы у тюрков средневековья.

Хирургические инструмены (скальпель и пинцет). Тюркская этномедицина включала в себя хирургические технологии. Можно предположить, что здесь производились хирургические операции вскрытия и зашивания мягких тканей, о чем свидетельствует отверстие для медицинской нити (изготовлявшейся, скорее всего, из кожи животных) на макушке пинцета.

Ритуальные сосуды, герметичные изнутри, с нефункциональным сливом у ручки, представляющие ценность, как артефакты материальной культуры, воплощающие обратную зеркальность инобытия и, скорее всего, использовавшиеся в сакральных практиках (рис. 4). В сосуде заключен семиотический код, характерный 


\section{ҚАЗАҚСТАН АРХЕОЛОГИЯСЫ № 1-2 2018}

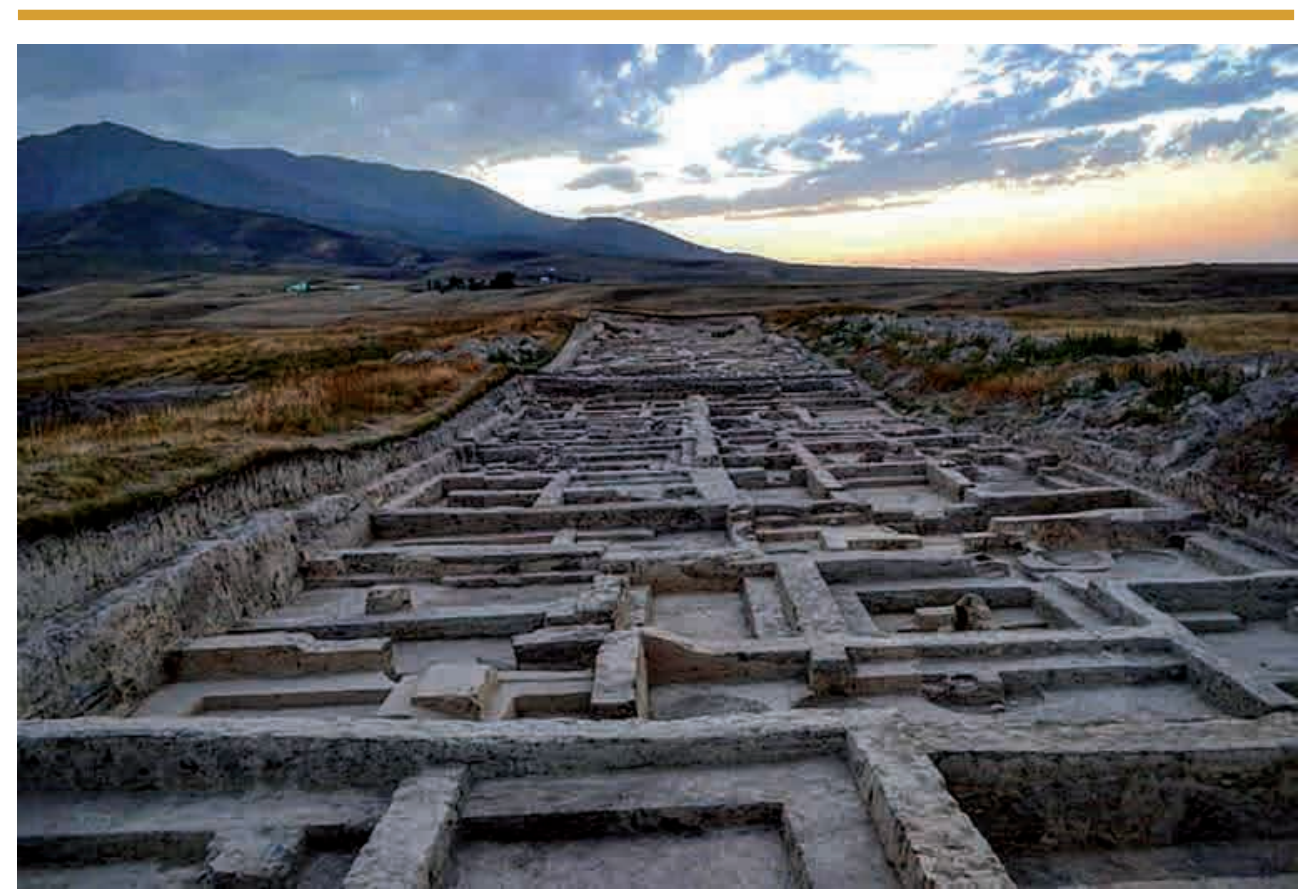

Рис. 2. Городище Кастек. Раскоп. Вид с востока. Фото А.А. Нуржанова

Fig. 2. Kastek settlement. Excavation. View from the east. Photo by Nurzhanov A.A.

для всего, что сообщается с «иными мирами», где все становится зеркально обратным (разбитая в погребении ритуальная чаша восстанавливается, покойный сидит на быке задом наперед, с невестой во время свадебных обрядов общаются через ее отражение в зеркале и т.д.).

Предметы вооружения представлены наконечниками копий, дротиков, стрел (рис. 5). По функциональному назначению копья относятся к колющему древковому оружию ближнего боя. Длина оружия от 15 до 20 см, длина пера 8-15 см, диаметр втулки 3-4 см. Втульчатая часть орудия имеет «сомкнутый шов». Копье было непременной принадлежностью тяжеловооруженного всадника, принадлежало к излюбленному и одному из основных видов оружия средневековых кочевников. В арабских письменных источниках особо отмечается, что копье тюрков короткое и полое. А короткие копья пронзают с большей силой и более легки для ношения.

По этнографическим данным копье (туу, найза) играло определенную роль в погребально-поминальном обряде казахов и киргизов. Наряду с любимым конем и одеждой оно выступало в качестве временного заместителя покойного. На сороковой день сквозь кошму юрты продевалось копье или деревянный шест с привязанным белым или красным платком (либо собственным знаменем умершего), что указывало на траур. После окончания траура копье преломлялось. На могиле копья не устанавливались.

Ножи. Относятся к одной из наиболее массовых категорий сопроводительного инвентаря. Все ножи достаточно однотипны: однолезвийные, черешковые, спинка прямая, а лезвие иногда вогнуто. Ширина лезвия 1,5-2 см, длина 12-14 см. При 
Нуржсанов $\boldsymbol{A . A . ~ К ~ в о п р о с у ~ о ~ с е м и о т и к е ~ п р о с т р а н с т в а ~ с р е д н е в е к о в о г о ~ г о р о д и щ а ~ К а с т е к . . . ~}$

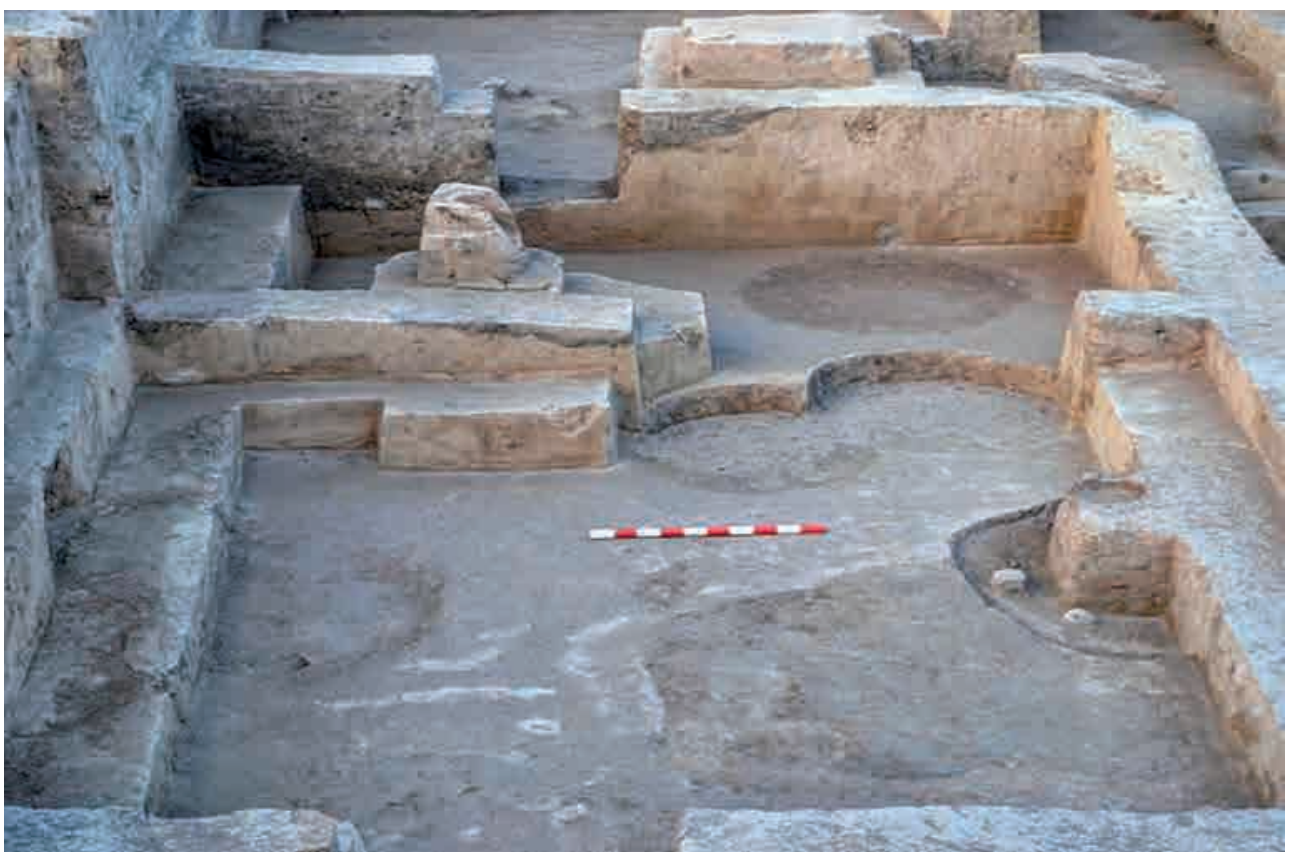

Рис. 3. Городище Кастек. Ритуальное помещение карлукского периода. Фото А.А. Нуржанова

Fig. 3. Kastek settlement. The ritual room of the Karluk period. Photo by Nurzhanov A.A.

переходе к черешку имеется выступ с одной, либо с двух сторон.

Наконечники стрел. Железные наконечники стрел относятся к черешковым и делятся по типу и форме пера. Наиболее распространенными являются трехлопастные наконечники с различной формой пера. Трехлопастные наконечники с небольшими изменениями (в конце I - начале II тыс. н.э. становятся более массивными) применялись в течение всей второй половины I тыс. н.э. Часть из них имеет отверстия в лопастях, как считается для усиления вращения стрелы в полете. О попадании крутящейся тюркской стрелы сообщается и в письменных источниках. Многие наконечники снабжены полыми шариками, свистунками, каждый из которых, как известно, мог служить муфтой, а также производил прон- зительный свист при полете стрелы. Как правило, свистунками оснащены трехлопастные наконечники. Интересной является находка рогов и останков диких копытных животных, что свидетельствует о практиках охоты среди местной аристократии.

У северо-восточной стены расположен глиняный алтарь с двумя полуовальными ступенями. На верхней плоскости алтаря - углубление в виде чаши из обожженной глины диаметром 40 см. Поверхность чаши украшена наклонными прочерченными линиями. С двух сторон от нее находятся два шишковидных выступа диаметром около 8 см. На полу вблизи алтаря очаг диаметром 52 см. У входа в помещение стоял керамический сосуд с отбитым верхом. Вдоль северной стены расположена суфа шириной 80 см. Помещение 1 объединяется проходами с помещениями 2 и 3. 


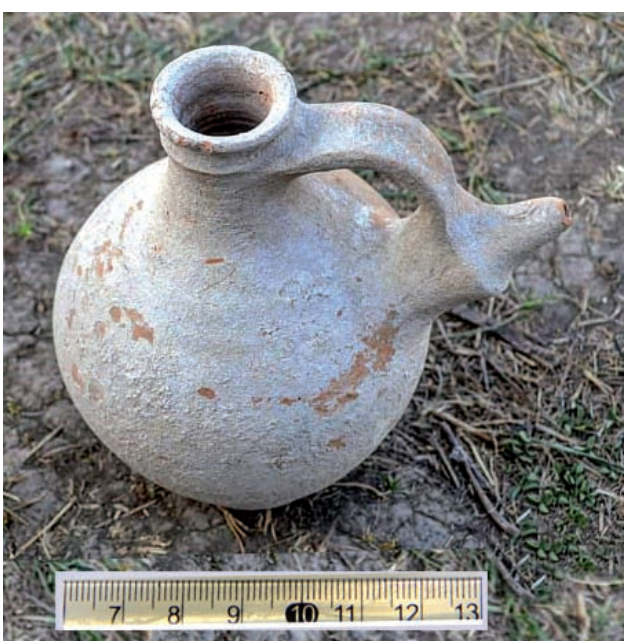

Рис. 4. Городище Кастек. Ритуальный сосуд. Фото А.А. Нуржанова

Fig. 4. Kastek settlement. The ritual vessel. Photo by Nurzhanov A.A.

Глиняные двух- и трехступенчатые алтари известны на средневековых памятниках Средней Азии, Южного Казахстана и Юго-Западного Жетысу. Археологические исследования показали, что подобные алтари могли использоваться по-разному: на одних возжигался огонь, на других устанавливались скульптурные изображения, символы богов, возлагались дары, производились воскурения. Форма жертвенников нишеобразных или арочных очертаний, подобная форме двухступенчатого алтаря из Кастек-1, объясняется единой с нишами символикой [Нуржанов, Терновая, 2014, c. 312-316].

Присутствие в материалах городища Кастек-1 двухступенчатого алтаря, предназначенного для воскурений, найденные в непосредственной близости от него предметы: керамический сосуд с семенами конопли, небольшой керамический сосудцедилка с отверстиями в тулове, культовый сосуд с носиком в виде головы волка (или собаки), медный котелок с растительным орнаментом и другие предметы, помогают в какой-то степени реконструировать сакральные обряды и религиозные представления жителей Жетысу в VIII-IX вв.

К отличительным признакам оформления алтаря из архитектурного комплекса Кастек-1 относятся шишковидные выступы, расположенные с двух сторон от углублениячаши. Выступы на разных жертвенниках имеют значение рогов, которые были одной из самых сакральных частей алтаря.

На памятниках джетыасарской культуры площадь одной из жилых секций служила культовым или общественным помещением. В середине таких помещений находились напольные очаги. К очагам овальной формы примыкали прямоугольные площадки с двумя шишковидными выступами. Очаги меньшего размера были встроены в центре полов джетыасарских склепов второго типа. Они имели прямоугольную, круглую или нишеобразную форму. Нередко в передней части очагов или перед ними помещали прямоугольные в плане плитки из обожженной глины с двумя трехступенчатыми пирамидками на концах. Перед плитками находились курильницы на высокой нож-

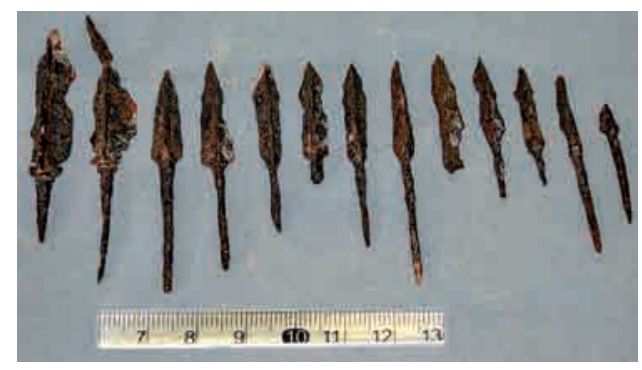

Рис. 5. Городище Кастек. Наконечники стрел. Фото А.А. Нуржанова

Fig. 5. Kastek settlement. The arrowheads. Photo by Nurzhanov A.A. 
Нуржанов А.А. К вопросу о семиотике пространства средневекового городища Кастек...

ке, но нигде не было зафиксировано непосредственной связи курильниц с «алтариками» [Левина, 1996, с. 27, 81, 249].

Парные выступы отмечены в оформлении алтаря из помещения культового комплекса, открытого на цитадели раннесредневекового городища Сидак в Южном Казахстане. Е.А. Смагулов сравнил выступы с плитками-«алтариками» из джетыасарских склепов и с «очажными подставками» или «шашлычницами», оформленными изображениями голов рогатых животных [Смагулов, 2005 , с. 489]. Появление «очажных подставок» относится к первому этапу культуры Каунчи, т. е. к первым векам до н.э. Находки подобных вещей встречаются также на памятниках раннего средневековья. В жилых помещениях городища Куйрыктобе X-XI вв. на площадках в «верхней» части напольных очагов расположены пирамидальные шишечки, предположительно имеющие значение «рогов» жертвенника [Байпаков, Терновая, 2005, c. 150].

В жилом комплексе X в. городища Джанкент в помещении 6 к стенке прямоугольного очага была приставлена керамическая «очажная подставка» с изображением двухголового барана. В площадке очагов перед подставками были вкопаны керамические сосуды, заполненные спекшейся золой [Зиливинская, 2013, c. 103-105].

В глиняном ступенчатом алтаре из Кастек-1 воплощены представления о трех ступенях мироздания. C «нижним миром» соотносится напольный очаг, со «средним» и «верхним» мирами - две ступени жертвенника. В данном случае архитектура является текстом культуры, прочесть который могут адепты этой культуры.
Знаковая система, закодированная в устройстве этого алтаря, диктуется не только его архитектурой, но и функциональностью. Исходя из устройства жертвенника-алтаря, можно предположить, что он использовался для воскурений. В соседнем помещении 2 был найден керамический сосуд с семенами конопли.

Об обрядах воскурения конопли есть сведения в письменных источниках [Геродот, 1972, с. 205]. Археологические подтверждения имеются в материалах Пазырыкских курганов (VI-III вв. до н.э.) [Руденко, 1952, c. 243]. По мнению Н.В. Полосьмак, небольшой медный котелок из Пазырыка использовался как переносная курильница для воскурения конопли, либо других галлюциногенов. Подобные медные котелки были обнаружены на Памире и в Индостане, встречаются также в памятниках ранних кочевников Южной Сибири (Тува, Минусинская и Кузнецкая котловина), в Семиречье [Полосьмак, 2006]. К интересным находкам на городище Кастек-1 относится медный котелок, украшенный растительным орнаментом. Таким образом, мы видим, что алтарь воплощает свою сакральную функцию портала в другие миры не только архитектурно (три ступени мироздания), но и с помощью психоактивных растений, воскуряя которые, служители культа становились психопомпами и проводниками в сферы сакрального. Семиотическая система здесь действует в едином комплексе материального и ментального.

Ментальная и материальная культуры горожан тюркских каганатов, с одной стороны, прошла несколько этапов своей эволюции, с другой, как и любая культура, развивалась в активном взаимодействии и взаимовлиянии с культурами других 
народов, как родственных кочевых, так и оседлых (согдийская, китайская). Оба эти процесса нашли отражение в археологическом материале.

В пору тюркского каганата и последующих этнокультурных и государственных образований с тюркоязычной политической доминантой этот процесс все более усиливался. В домонгольскую эпоху здесь прочно складывается локальный урбанистический комплекс с общемусульманскими стандартами и эталонами в его средневековом воплощении, пестрым многоязычием и этнической ассимиляцией согдийцев и различных тюркоязычных народов в рамках Караханидского государства, которое являет собой образец средневековой урбанизированной культуры.

Важный пласт культурного наследия связан с Казахским ханством, его культурой, базировавшейся на традициях кочевого быта и культуре городов и селений сырдарьинскосемиреченского региона. Возникновение культуры города и степи в Казахском ханстве - одно из ярких явлений культурогенеза Казахстана.

Историко-археологическое исследование средневековых городов Юго-Восточного Казахстана позволяет реконструировать процессы взаимоотношений различных культурных традиций, расширить базу доказательств того, что территория Казахстана была одним из центров историко-культурного синтеза, взаимодействие кочевого и оседлого населения привело к взаимообогащению культур. Именно в недрах такого симбиоза лежат многие достижения культуры народов Казахстана.

Таким образом, семиосфера средневекового города Кастек представляет собой гетерогенное пространство, генерирующее самые разные сегменты культуры (аутентичной, заимствованной, синкретичной), воплощенные как в архитектуре города, так и в артефактах, обнаруженных на его территории. Средневековый город Кастек много веков являлся одним из центров Западно-Тюркского и Карлукского каганатов и Караханидского государства. Функциональный анализ артефактов, полученных в результате историко-археологических исследований, доказывает, что в этом регионе существовал оазис городской культуры тюркских государств. Здесь города и степь, земледелие и скотоводство развивались в едином политическом, хозяйственно-экономическом и социокультурном комплексе.

\section{ЛИТЕРАТУРА}

1. Байпаков К.М., Терновая Г.А. Религии и культы средневекового Казахстана. Алматы: Изд-во «Баур», 2005. 236 с.

2. Бичурин Н.Я. Собрание сведений о народах, обитавших в Средней Азии в древние времена. Т. 1. М.-Л.: изд-во АН СССР. 1950. 382 с.

3. Геродот. История в девяти книгах. / Перевод и примеч. Г.А. Стратановского. 4 кн. Л.: Наука, 1972. 600 с.

4. Зиливинская Э.Д. Очаги жилого комплекса на городище Джанкент // Известия НАН РК. Сер. обществ. и гуманит. наук. 2013. № 3 (289). С. 100-109.

5. Левина Л.М. Этнокультурная история Восточного Приаралья (в первом тысячелетии н.э.). М.: Вост.лит., 1996. 398 с.

6. Нуржанов А.А., Терновая Г.А. К вопросу об обрядовой практике жителей Жетысу (Семиречья) в VIII-IX вв. // Труды «IV» XX Всеросссийского археологического съезда. Казань: «Отечество», 2014, Т. 2. С. 312-316. 
Нуржанов А.А. К вопросу о семиотике пространства средневекового городища Кастек...

7. Полосьмак Н.В. Жизнь и смерть пазырыкцев Укока: междисциплинарные исследования материалов из Пазырыкских курганов с «замерзшими» могилами на плато Укок, Горный Алтай (конец IV - III в. до н.э.) // Вестник истории, литературы, искусства. 2006. Т.3. с.7-18.

8. Руденко С.И. Горноалтайские находки и скифы. М.; Л.: Изд-во АН СССР, 1952. $268 \mathrm{c}$.

9. Смагулов Е.А. Исследования доисламского храмового комплекса на городище Сидак // Культурное наследие Казахстана. Открытия, проблемы, перспективы. Алматы: Вестник КазНПУ им. Абая, 2005. С. 486-491.

\section{Сведения об авторе:}

Нуржанов Арнабай Абишевич - кандидат исторических наук, ведущий научный сотрудник, Институт археологии им. А.Х. Маргулана (г. Алматы, Казахстан); arnabai@mail.ru

\section{ОРТАҒАСЫРЛЫҚ ҚАСТЕК ҚАЛАСЫНЫН АУМАҚТЫҚ СЕМИОТИКАСЫ ТУРАЛЫ МӘСЕЛЕГЕ: АРТЕФАКТІЛЕРДІ ФУНКЦИОНАЛДЫ ТАЛДАУ}

\section{А.А. Нұржанов}

Мақалада ортағасырлық Қастек қаласына семиотикалық талдау жасалған. Түрік қағанаттары дәуірі кезінде отырықшы қала мәдениеттерінің шеткі аумақтарында кенттену үрдістерінің дамуы көрсетіледі. XIII ғасырға дейін бұл аумақтарда мұсылман дінінің қабылдауына байланысты, соғды түрік халықтары арасындағы мәдени-этникалық қарым-қатынастар урбанизацияның басты өркениетін көрсетеді. Артефактілерді талдау арқалы Жетісу түріктерінің ғұрыптық және күнделікті өмір салттарына талдау жасалды. Артефактілерді талдау барысында халықтардың рухани дүниесінде заттардың ерекше орын алғандығы белгілі болып отыр.

Түйін сөздер: археология, Жетісу, ортағасыр, аумақтық семиотика, ортағасырлық кенттену, түріктер, қарлұқтар, қараханидтер, түріктердің қала мәдениеті, дін, өркениет, сакралды артефактілер

\section{TO THE QUESTION ABOUT SEMIOTICS OF THE SPACE OF THE KASTEK SETTLEMENT: FUNCTIONAL ANALYSIS OF ARTIFACTS}

\section{A.A. Nurzhanov}

The article provides a semiotic analysis of the urban space of the medieval city of Kastek. In the era of the Turkic Kaganate and subsequent ethnocultural and state formations with a Turkic political dominant, the process of urbanization in the marginal zones of the sedentary agricultural culture intensified. In the pre-Mongol era, the local urban complex with general Muslim standards and standards in its medieval incarnation, motley multilingualism and ethnic assimilation of Sogdians and various Turkic-speaking peoples within the Karakhanid state, which is a model of medieval urbanized culture, is firmly established. Also on the materials of artifacts found during the excavations, reconstruction of some ritual and everyday practices characteristic of the urban culture of the medieval Turks Zhetysu was made. The functional analysis of artifacts proves that utilitarian objects and actions in traditional culture are imbued with symbols and there are equally, both everyday objects and sacred works of art of the urban culture of the Turks.

Keywords: archaeology, Jetysu, Middle Ages, semiotics of space, medieval urbanism, Turks, Karluks, Karakhanids, Turkic urban culture, religion, civilization, sacred artifacts 


\section{REFERENCES}

1. Baipakov, K. M., Ternovaya, G. A. 2005. Religii i kul'ty srednevekovogo Kazakhstana. (Religions and cults of medieval Kazakhstan). Almaty: «Baur» Publ. (in Russian).

2. Bichurin, N. Ya. 1950. Sobraniye svedeniy o narodah, obitavshih v Sredney Azii $v$ drevniye vremena (Collection of information about the peoples who lived in Central Asia in ancient times), 1. Moscow-Leningrad: Academy of Sciences of the USSR (in Russian).

3. Gerodot. 1972. Istoriya v devyati knigakh. (The history in nine books) / Translation and footnotes Stratanovsky, G. A. 4 kn. Leningrad: "Nauka" Publ. (in Russian).

4. Zilivinskaya, E. D. 2013. In Izvestiya Akademii nauk Kazahstana (News of the National Academy of Sciences of Kazakhstan. Ser. societies. and humanity. Sciences), 3 (289), 100-109 (in Russian).

5. Levina, L. M. 1996. Etnokul'turnaya istoriya Vostochnogo Priaral'ya (v pervom tysyacheletii n.e.) (Ethnocultural history of Eastern Aral (in the first millennium AD)). Moscow: "Vostochnaya literature" Publ. (in Russian).

6. Nurzhanov, A. A., Ternovaya, G. A. 2014. In Trudy «IV»20 th Vserosssiiskogo arheologicheskogo s'ezda (Proceedings of the "IV" of the XX All-Russian Archeological Congress), 2. Kazan: "Otechectvo" Publ., 312-316 (in Russian).

7. Polos'mak, N. V. 2006. In Vestnik istorii, literatury, iskusstva (History Bulletin of literature, art), 3, 7-18 (in Russian).

8. Rudenko, S. I. 1952. Gornoaltayskiye nakhodki $i$ skify (Altai finds and Scythians). Moscow-Leningrad: Academy of Sciences of the USSR (in Russian).

9. Smagulov, Ye. A. 2005. In Kul'turnoe nasledie Kazahstana. Otkrytiya, problemy, perspektivy (Cultural heritage of Kazakhstan. Discoveries, problems, prospects). Almaty: Bulletin Kazakh National Pedagogical University named Abay, 486-491 (in Russian).

\section{About the Author:}

Nurzhanov Arnabay A. Candidate of Historical Sciences, Leading Researcher, A.Kh. Margulan Archeology Institute, Almaty, Kazakhstan; arnabai@mail.ru

\footnotetext{
Мүдделер қақтығысы туралы ақпаратты ашу. Автор мүдделер қақтығысының жоқтығын мәлімдейді. / Раскрытие информации о конфликте интересов. Автор заявляет об отсутствии конфликта интересов. / Disclosure of conflict of interest information. The author claims no conflict of interest.

Мақала туралы ақпарат / Информация о статье / Information about the article. Редакцияға түсті / Поступила в редакцию / Entered the editorial office: 15.10.2018. Рецензенттер мақұлдаған / Одобрено рецензентами / Approved by reviewers: 22.10.2018. Жариялауға қабылданды / Принята к публикации / Accepted for publication: 25.10.2018.
} 